\title{
Estudo sobre a aplicabilidade de adesivos biológicos à reinserção de músculo ocular externo em coelhos - II Experimento II - Medida das distâncias das bordas nasal e temporal do músculo ao limbo e da extensão da adesão tecidual
}

\author{
A study of the applicability of biological adhesives to the insertion of an \\ external ocular muscle in rabbits - II \\ Experiment II-Measurement of the distances from the nasal and temporal muscles \\ to the limbus and of the extent of tissue adhesion
}

\author{
Beatriz Simões Corrêa ${ }^{1}$ \\ Harley Edson Amaral Bicas ${ }^{2}$
}

Trabalho realizado na Faculdade de Medicina de Ribeirão Preto da Universidade de São Paulo.

Resumo da segunda parte da Tese de Doutorado apresentada ao Departamento de Oftalmologia, Otorrinolaringologia e Cirurgia de Cabeça e Pescoço, Faculdade de Medicina de Ribeirão Preto da Universidade de São Paulo.

Pós-graduada (Doutorado) do Departamento de Oftalmologia, Otorrinolaringologia e Cirurgia de Cabeça e Pescoço, Faculdade de Medicina de Ribeirão Preto da Universidade de São Paulo (USP). Ribeirão Preto (SP).

Professor Titular do Departamento de Oftalmologia, Otorrinolaringologia e Cirurgia de Cabeça e Pescoço, Faculdade de Medicina de Ribeirão Preto da USP. Ribeirão Preto $(\mathrm{SP})$.

Endereço para correspondência: Beatriz Simões Corrêa - Av. Afrânio de Melo Franco, 141/408 - Rio de Janeiro (RJ) CEP 22430-060

E-mail: bscoftalmo@uol.com.br

Recebido para publicação em 27.08.2003

Versão revisada recebida em 13.04.2005

Aprovação em 12.07.2005

Nota Editorial: Depois de concluída a análise do artigo sob sigilo editorial e com a anuência da Dra. Célia Regina Nakanami sobre a divulgação de seu nome como revisora, agradecemos sua participação neste processo.

\section{RESUMO}

Objetivo: Medir a extensão de aderências mioesclerais no quadragésimo dia de pós-operatório. Métodos: Quinze coelhos da raça Nova Zelândia foram distribuídos em três grupos de cinco coelhos, submetidos à operação de desinserção do músculo reto superior de ambos os olhos, e reposicionamento no local da inserção original: o Grupo SP para o controle, sutura com fio de poliglactina 910 (Vicryl ${ }^{\circledR}$ 6-0), Grupo AF, adesivo de fibrina (Beriplast- $\mathrm{P}^{\circledR}$ ), e Grupo AC, adesivo de cianoacrilato (Histoacryl ${ }^{\circledR}$ ). Antes da desinserção muscular, foram medidas as distâncias do gancho sob o músculo ao limbo, borda medial e lateral. Após quarenta e cinco dias, estes olhos foram reoperados e as medidas realizadas novamente. Resultados: Não houve diferença significativa entre os adesivos estudados, quanto à adesão tecidual e às distâncias encontradas do músculo ao limbo nos pré- e pós-operatórios. Conclusões: As aderências teciduais encontradas foram provavelmente devidas aos processos de cicatrização, não dependendo dos materiais estudados.

Descritores: Adesivos teciduais, Adesivo tecidual de fibrina; Cianoacrilatos; Músculos oculomotores/cirurgia; Nervo oftálmico; Coelhos

\section{INTRODUÇÃO}

Como vimos na primeira parte deste trabalho, poucas foram as referências encontradas a respeito dos adesivos biológicos empregados em músculos oculares externos. Estudamos nessa primeira parte: 1) o tempo gasto para realizar operações de recuo de reto superior de coelhos em ambos os olhos, 2) a força necessária para romper a junção mioescleral refixada, 3) os aspectos clínicos e 4) os aspectos histopatológicos, com: a sutura de poliglactina 910, e com adesivos de fibrina, de cianoacrilato, de albuminaglutaraldeído e de gelatina-resorcinol-glutaraldeído-formaldeído.

As observações que descrevemos, sobre a resistência dos materiais, justificam comparar a adesão tecidual das duas colas biológicas que apresentaram melhor desempenho, a de fibrina e a de cianoacrilato, com o 
controle, para verificar se há escorregamento muscular, ou aderências indesejáveis.

Não localizamos na literatura medidas da extensão da reinserção muscular. Sendo os adesivos materiais usados em estado viscoso, poderiam se espalhar além do local em que foram colocados, causando adesões indesejáveis?

Neste estudo, comparamos as medidas das distâncias das bordas medial e lateral do músculo ao limbo durante a operação, com os resultados encontrados no quadragésimo dia de pós-operatório, dos adesivos de cianoacrilato, de fibrina, comparando-os à sutura com fio de poliglactina 910 (controle).

\section{MÉTODOS}

\section{Descrição da amostra}

Quinze coelhos (trinta olhos), cinco para o método de referência (sutura) e cinco para cada um dos dois adesivos, de fibrina e de cianoacrilato, formaram três grupos:

a) Grupo SP: sutura de poliglactina 910 (Vicryl ${ }^{\circledR}$ 6-0), controle; b) Grupo AF: cola de fibrina (Beriplast-P ${ }^{\circledR}$ ) e c) Grupo AC: cola de cianoacrilato (Histoacryl ${ }^{\circledR}$ ).

Foram observados os critérios de cuidados com animais da Association for Research in Vision and Ophthalmology (ARVO) para a realização desse experimento.

Os procedimentos cirúrgicos básicos já foram descritos na primeira parte do trabalho. Acrescentamos a estes procedimentos, as medições das distâncias do gancho sob o músculo ao limbo, das bordas medial e lateral, antes da desinserção.

\section{Revisão das operações}

No quadragésimo quinto dia os olhos dos coelhos foram reoperados, da seguinte maneira:

1. Da anestesia à abertura conjuntival, conforme descrito para a operação.

2. Medidas da distância do gancho sob o músculo ao limbo, das bordas medial e lateral, com o objetivo de verificar aderências além do local da colocação do adesivo.

\section{Métodos estatísticos}

Foram verificadas, para cada grupo, as médias aritméticas entre as diferenças das distâncias do limbo ao gancho, na borda lateral e na borda medial, antes da operação, e na revisão cirúrgica de quarenta e cinco dias.

Foi feita inferência estatística com o teste do Qui-quadrado para várias proporções.

\section{RESULTADOS}

Os resultados estão apresentados na tabela 1 . O gráfico 'box-plot' apresentado, exibe, no retângulo, a mediana, o primeiro e o terceiro quartis. Exibe, ainda, o valor menor e o maior, respectivamente, pelo limite inferior e superior das linhas retas verticais, que se originam do primeiro e terceiro quartis.

Aplicado o teste do Qui-quadrado para várias proporções, a conclusão foi de que não houve diferença significativa entre as medidas das distâncias das bordas medial e lateral do músculo ao limbo, bem como da extensão da adesão tecidual, entre os materiais estudados.

\section{DISCUSSÃO}

Questionamos se as diferentes intensidades do processo inflamatório, apresentadas pelos três materiais, e suas diferentes características físicas poderiam provocar diferentes formas de adesão tecidual e, com isso, comprometer o resultado final das operações de reinserção ocular dos retos superiores de coelhos.

Em princípio, a poliglactina, como sutura, talvez pudesse garantir uma adesão músculo-escleral mais uniforme, pois os adesivos, viscosos, não nos permitiram controlar a extensão de seu espalhamento. Apesar de ser o adesivo de cianoacrilato suficientemente viscoso para que não escorra, isso pode acontecer. Também é menos elástico que o adesivo fibrínico, podendo quebrar-se com facilidade se as estruturas aderidas moverem-se. Segundo Dunlap et al., estudando as reações

\begin{tabular}{|c|c|c|c|c|c|c|c|c|c|c|c|c|}
\hline & \multicolumn{4}{|c|}{ Poliglactina 910 6-0 } & \multicolumn{4}{|c|}{ Cianoacrilato } & \multicolumn{4}{|c|}{ Fibrina } \\
\hline & $\begin{array}{l}\text { Medial } \\
\text { cirurgia }\end{array}$ & $\begin{array}{c}\text { Medial } \\
\text { revisão }\end{array}$ & $\begin{array}{l}\text { Lateral } \\
\text { cirurgia }\end{array}$ & $\begin{array}{l}\text { Lateral } \\
\text { revisão }\end{array}$ & $\begin{array}{l}\text { Medial } \\
\text { cirurgia }\end{array}$ & $\begin{array}{l}\text { Medial } \\
\text { revisão }\end{array}$ & $\begin{array}{l}\text { Lateral } \\
\text { cirurgia }\end{array}$ & $\begin{array}{l}\text { Lateral } \\
\text { revisão }\end{array}$ & $\begin{array}{l}\text { Medial } \\
\text { cirurgia }\end{array}$ & $\begin{array}{c}\text { Medial } \\
\text { revisão }\end{array}$ & $\begin{array}{l}\text { Lateral } \\
\text { cirurgia }\end{array}$ & $\begin{array}{c}\text { lateral } \\
\text { revisão }\end{array}$ \\
\hline & 1,5 & 3,5 & 1,0 & 4,0 & 1,5 & 4,5 & 1,5 & 5,5 & 1,5 & 3,5 & 1,5 & 4,0 \\
\hline & 1,5 & 4,0 & 1,5 & 4,0 & 1,5 & 4,0 & 1,5 & 3,0 & 1,5 & 4,5 & 1,5 & 6,0 \\
\hline & 1,5 & 6,0 & 1,5 & 6,0 & 1,5 & 6,0 & 1,5 & 6,0 & 1,5 & 6,0 & 1,5 & 5,5 \\
\hline & 1,5 & 3,5 & 1,5 & 3,0 & 1,5 & 5,0 & 1,5 & 5,0 & 1,5 & 6,5 & 1,5 & 6,0 \\
\hline & 2,0 & 6,5 & 2,0 & 5,5 & 1,5 & 4,0 & 1,5 & 6,0 & 2,0 & 3,5 & 2,0 & 4,0 \\
\hline & 1,5 & 3,0 & 1,5 & 3,0 & 2,0 & 3,0 & 2,0 & 3,0 & 1,5 & 5,0 & 1,5 & 4,0 \\
\hline & 1,5 & 4,0 & 1,5 & 4,0 & 2,0 & 5,0 & 2,0 & 5,0 & 2,0 & 7,0 & 2,0 & 4,0 \\
\hline $\mathrm{m}$ & 1,1 & 4,2 & 1,1 & 4,2 & 1,4 & 5,1 & 1,4 & 5,1 & 1,3 & 4,9 & 1,3 & 4,9 \\
\hline
\end{tabular}




\section{CONCLUSÃO}

Não houve diferenças, quanto à extensão da adesão mioescleral entre os materiais estudados.

\section{AGRADECIMENTOS}

Aos colegas Olavo Gomes Pereira Filho e Cláudio Shinzato, pela colaboração nos procedimentos cirúrgicos. Aos Laboratórios que nos ofereceram seus adesivos: Centeon, o Beriplast- $\mathrm{P}^{\circledR}$; B. Braun, o Histoacryl ${ }^{\circledR}$; Cryolife

\section{ABSTRACT}

Purpose: Measure the extent of mioscleral adhesion on the fourtieth postoperative day. Methods: Fifteen New Zealand rabbits were divided into three groups of five rabbits. They were operated on to server the insertion of the rectus muscle in the eye and then to reinsert it. Group SP, polyglactin (Vi$\mathrm{cryl}^{\circledR}$ ) was used as control. In group AF, fibrin adhesive (Beriplast- $\left.\mathrm{P}^{\circledR}\right)$ was used, and in group AC, cyanoacrylate adhesive $\left(\right.$ Histoacryl ${ }^{\circledR}$ ). Before severing muscle insertion, the distances between the muscle attachments of the limbus to the medial and lateral borders were measured. After forty-five days, the operation was again performed and the measurements were taken once more. Results: There was no significant difference between the studied adhesives in terms of tissue adhesion and of the distances from the muscle to the limbus before and after surgery. Conclusion: The found tissue adhesion was probably due to the scarring process and was not dependent on the studied materials.

Keywords: Tissue adhesives; Fibrin tissue adhesive; Cyanoacrylates; Oculomotor muscles/surgery; Ophthalmic nerve; Rabbits

manipular os tecidos, podem ser modificadores da extensão da adesão músculo-escleral.

Nesta comparação que fizemos dos adesivos de fibrina, de cianoacrilato e da sutura de poliglactina, quanto à extensão da adesão músculo-escleral após os 45 dias de pós-operatório,o gráfico apresentado mostra, para um mesmo material, diferenças na adesão entre as bordas medial e lateral, e para o adesivo fibrínico, valores maiores de adesão tecidual que para os outros materiais. Os testes estatísticos aplicados no entanto não mostraram haver diferença entre os materiais estudados.

\footnotetext{
REFERÊNCIAS

1. Dunlap EA, Dunn M, Rossomondo R. Adhesives for sutureless muscle surgery. Arch Ophthalmol. 1969;82(6):751-5.

2. Ingram RM. Rate at which muscle becomes joined to sclera after operations of recession and resection. Br J Ophthalmol. 1965;49:235-45.

3. Santiago AP, Rosenbaum AL Strabismus reoperation: strategies and techniques. In: Rosenbaum, S. Clinical strabismus management: principles and surgical techniques. Philadelphia: W.B. Saunders; 1999. p.507-15.

4. Reinecke RD, Tarakji M. Adhesive strabismus syndrome (cicatricial strabismus): surgical results. In: Helveston EM; New Orleans Academy of Ophthalmology. Symposium on strabismus: Transactions of the New Orleans Academy of Ophthalmology. St Louis: C V Mosby; 1978. p.280-4.
} 